BMJ Open Diabetes Research \& Care

\section{Extracellular Hsp90a, which participates in vascular inflammation, is a novel serum predictor of atherosclerosis in type 2 diabetes}

To cite: Ding X, Meng C Dong $\mathrm{H}$, et al. Extracellular Hsp90 $\alpha$, which participates in vascular inflammation, is a novel serum predictor of atherosclerosis in type 2 diabetes. BMJ Open Diab Res Care 2022;10:e002579. doi:10.1136/ bmjdrc-2021-002579

- Additional supplemental material is published online only. To view, please visit the journal online (http://dx.doi. org/10.1136/bmjdrc-2021002579 ).

$\mathrm{XD}, \mathrm{CM}$ and $\mathrm{HD}$ contributed equally.

Received 31 August 2021 Accepted 3 January 2022

Check for updates

C A Author(s) (or their employer(s)) 2022. Re-use permitted under CC BY-NC. No commercial re-use. See rights and permissions. Published by BMJ.

For numbered affiliations see end of article.

Correspondence to Dr MengChen Zou; zoumc163@163.com, Fei Zou; zfei@smu.edu.cn and Wei Li; wli@usc.edu

\section{ABSTRACT}

Introduction Atherosclerosis is the main pathological change in diabetic angiopathy, and vascular inflammation plays an important role in early atherosclerosis. Extracellular heat shock protein 90 (eHsp90) is secreted into the serum and is involved in various physiological and pathophysiological processes. However, the specific mechanism of eHsp90 in early atherosclerosis remains unclear. This study explored the relationship between Hsp90 and diabetic lower extremity arterial disease and investigated the expression of eHsp90 in vascular endothelial cells under environmental stimulation and the function and mechanism of eHsp90 $\alpha$ involved in diabetic atherosclerosis. Research design and methods One hundred and three selected patients were divided into three groups: the diabetes mellitus group $(n=27)$, the diabetic lower extremity arterial disease group $(n=46)$, and the diabetic critical limb ischemia group $(\mathrm{n}=30)$. The relationships among serum Hsp90, oxidative stress indexes, and patient outcomes and the correlations among the indexes were analyzed. H\&E staining and immunohistochemistry were used to observe the vasculature of amputated feet from patients with diabetic foot. An oxidative stress endothelial injury model was established under high glucose in vitro to explore the role of eHsp90 release in atherosclerosis progression. Results The level of serum Hsp90 was upregulated with aggravation of diabetic vascular disease. Hsp90 $\alpha$ was correlated with malondialdehyde to some extent and was an independent risk factor in the progression of diabetic vascular disease, with predictive ability. The expression area of $\mathrm{Hsp} 90 \alpha$ was consistent with the area of inflammatory infiltration in the vessel lumen. Vascular endothelial cells were found to increase eHsp90 $\alpha$ secretion under stress. Then inhibition of eHsp90 $\alpha$ can reduce the degree of cellular inflammation and damage. Endothelial cell-conditioned medium and recombinant human $\mathrm{Hsp} 90 \alpha$ increased monocyte migration via the low-denisity lipoprotein receptor-related protein 1 (LRP1) receptor to promote disease progression.

Conclusions eHsp90 $\alpha$ plays a critical role in the early inflammatory injury stage of atherosclerosis. Trial registration number NCT04787770.

\section{INTRODUCTION}

Diabetes mellitus (DM) has become a global public health problem. Approximately 4.2

\section{Significance of this study}

What is already known about this subject?

$\Rightarrow$ Fewer than $10 \%$ of patients with diabetic lower extremity arterial disease (DLEAD) have typical clinical symptoms, with early diagnosis difficult and with lack of effective treatments affecting the patient's prognosis.

$\Rightarrow$ Recent studies suggest that heat shock protein 90 (Hsp90) inhibitors have a protective effect on diabetic complications.

$\Rightarrow$ The exogenous expression and role of extracellular Hsp90 in DLEAD are unclear.

What are the new findings?

$\Rightarrow$ Elevated serum Hsp90 $\alpha$ level is correlated with degree of oxidative stress and is an independent risk factor for progression of diabetic vascular disease, with predictive value, in patients with type 2 diabetes mellitus.

$\Rightarrow$ Both vascular inflammatory cell infiltration and elevated Hsp90 $\alpha$ expression were present in patients with diabetic critical limb ischemia.

$\Rightarrow$ Endothelial cell-derived extracellular Hsp90 $\alpha$ promotes inflammatory damage via the LRP1 receptor to trigger atherosclerosis.

How might these results change the focus of research or clinical practice?

$\Rightarrow$ Extracellular Hsp90 $\alpha$ might participate in atherosclerotic vascular inflammation in type 2 diabetes.

$\Rightarrow$ A novel serum predictor is proposed to provide new insight into inflammatory injury in the clinical diagnosis and treatment of diabetic macroangiopathy.

million people die each year from DM or its complications. ${ }^{1}$ Lower extremity arterial disease (LEAD) is the most common initial manifestation of cardiovascular disease in individuals with type 2 diabetes mellitus (T2DM) ${ }^{2}$ Up to $80 \%$ of people with T2DM die from cardiovascular complications, and the disease reduces the average life expectancy by 
approximately 10 years. ${ }^{3}$ Therefore, early prevention and diagnosis of LEAD is particularly important in patients with diabetes.

The initial pathogenesis of atherosclerosis (AS) includes the formation of advanced glycosylation end products, excessive production of reactive oxygen species (ROS), and other processes. ${ }^{4}$ The different pathogenic mechanisms induced by hyperglycemia all reflect a single upstream process, namely overproduction of ROS. ${ }^{5} \operatorname{Ross}^{6}$ proposed that AS is a pathological process characterized by a chronic inflammatory response. When the levels of metabolic abnormalities are increased, superoxide can also activate and participate in the pathogenesis of various complications. However, there is no marker reflecting the current states of the vascular endothelium and the inflammatory response that can be applied for early clinical detection, which makes early diagnosis difficult.

Heat shock protein 90 (Hsp90) is an important molecular chaperone that is widely involved in immune regulation. Lei $e t a l^{7}$ proposed that Hsp90 $\alpha$ is involved in the pathogenesis of diabetic angiopathy. In recent years, Hsp90 inhibitors have been found to have protective effects against diabetic angiopathy. For example, Lazaro $e t$ $a l^{8}$ reported that application of an Hsp90 inhibitor (Alvespimycin (17-DMAG)) effectively reduced renal injury in a diabetic mouse model. Kim et at found that inhibiting Hsp90 can reduce the formation of AS by inhibiting the migration and proliferation of vascular smooth muscle cells (VSMCs). Madrigal-Matute $e t a l^{10}$ found that Hsp90 is highly expressed in the thin fibrous cap area of human carotid atherosclerotic plaques. All the above findings suggest that Hsp90 may be a new target for AS therapy. Extracellular Hsp90 (eHsp90) has been reported to be involved in a variety of pathological processes and plays a different biological role than intracellular Hsp90. Our team found that eHsp90 can be released outside the cell through exosomes under stress conditions, which in turn affects cytoskeletal proteins to promote the migration of epithelial cells, participating in damage repair. ${ }^{11-13}$ Although Hsp90 has been indicated to be correlated with diabetic vascular disease, previous studies have focused more on its role as a molecular chaperone. Whether eHsp90 is involved in vascular inflammation or fibrosis is still unclear.

In this study, in vivo serological studies and in vitro cell models were used to explore the direct relationship between serum Hsp90 concentrations and subclinical AS in patients with T2DM and the role of eHsp90 $\alpha$ in diabetic vascular disease in an oxidative stress injury model. The findings will provide a new perspective for investigation into early therapeutic targets for diabetic vascular disease.

\section{RESEARCH DESIGN AND METHODS}

\section{Study subjects}

From August 30, 2019 to May 28, 2021, a total of 103 patients at the Endocrinology and Metabolism
Department of the Nanfang Hospital of Southern Medical University were randomly enrolled in this study. The patients were divided into three groups: the diabetes mellitus group (DM, 27 patients), the diabetic lower extremity arterial disease group (DLEAD, 46 patients), and the diabetic critical limb ischemia group (DCLI, 30 patients). The subjects were grouped according to their clinical presentations and imaging studies.

The following were the inclusion criteria:

- DM group:

- T2DM was diagnosed according to the WHO 1999 criteria.

- Screening for LEAD was performed in patients without a diagnosis of LEAD.

- DLEAD group: patients were diagnosed with T2DM according to the above DM diagnostic criteria and LEAD was diagnosed according to the International Working Group on the Diabetic Foot (IWGDF) 2019 guidelines on the basis of the following:

- Symptoms and signs of AS (intermittent claudication, resting pain, decreased or absent pulse in the dorsal foot artery, etc).

- An ankle-brachial arterial pressure index $(\mathrm{ABI})<0.9$, a toe-brachial arterial pressure index $<0.7$, no three-phase foot pulse graph waveform, or a percutaneous oxygen partial pressure $<30 \mathrm{~mm} \mathrm{Hg}$.

- Evidence of uneven thickening, AS, atherosclerotic plaques, arterial stenosis, or obstruction in the carotid and/or lower extremity arteries on vascular color Doppler ultrasonography.

- DCLI group: DCLI was diagnosed in patients who met the above diagnostic criteria for DLEAD and who had lower extremity ischemic infection, ulceration and/ or deep tissue destruction for more than 4 weeks, and an $\mathrm{ABI}<0.4$.

The patients and/or their families were informed and agreed to participate in the study. Patients were excluded if they met any of the following exclusion criteria before admission:

- History of diabetic ketoacidosis or hyperosmolar status within 30 days.

- History of diabetic coma within 3 months or any hypoglycemic event within 1 month.

- History of cancer, immune system disease, or any hypoglycemia event within 1 month.

- History of other types of DM.

- Age less than 18 years old.

\section{Sample collection}

Blood samples $(3 \mathrm{~mL})$ were collected under aseptic conditions from the peripheral veins of the subjects. Serum samples were obtained via cold centrifugation at 3000revolutions per minute ( $\mathrm{rpm}$ ) for $15 \mathrm{~min}$. The clear supernatants were stored at $-80^{\circ} \mathrm{C}$ until they were used for biochemical analysis. 
Assessment of Hsp90 $\alpha$ and $\mathrm{Hsp} 90 \mathrm{\beta}$

The levels of serum Hsp90 $\alpha$ and Hsp90 $\beta$ were measured using ELISA kit (JingKang Bio, China). All procedures were performed according to the manufacturer's instructions. Absorbance was measured at a wavelength of 450 $\mathrm{nm}$.

\section{Histopathology and immunohistochemistry}

Blood vessels were obtained from amputated tissue discarded during surgery from three patients with DCLI, immersed in paraformaldehyde for at least 24 hours for fixation, paraffin-embedded, and cut into $2 \mu \mathrm{m}$ sections. The samples were stained with HE for histopathological assessment. Immunohistochemistry for Hsp90 $\alpha$ was performed.

\section{Cell cullture}

Human umbilical vein endothelial cells (HUVECs) and the human monocyte line THP-1 were obtained from the China Center for Type Culture Collection. HUVECs were cultured in DMEM/F12 (Gibco, USA), and THP-1 cells were grown in Roswell Park Memorial Institute (RPMI) 1640 medium supplemented with $10 \%$ fetal bovine serum (FBS) (ExCell Bio, China) and 1\% penicillin/streptomycin in a $37^{\circ} \mathrm{C}$ incubator with a humidified atmosphere and $5 \% \mathrm{CO}_{2}$.

\section{Antibodies and reagents}

The primary antibodies included Hsp90 $\alpha$ (07-2174; Merck, USA), Hsp90 $\beta$ (SPC-177; StressMarq Biosciences, Canada), low-denisity lipoprotein receptor-related protein 1 (LRP1) (BS9805M; Bioworld Technology, USA), p-Akt (66444-Ig; Proteintech, USA), Akt (\#2920S; CST, USA), and $\beta$-actin (RM2001; RayBiotech, China).

The primary reagents included recombinant human Hsp90 $\alpha$ protein and recombinant human Hsp90ß protein (SPR-101C and SPR-102C; StressMarq, Canada) and 17-allyamino-17-demethoxygeldanamycin, (17AAG) (HY10211; MCE, USA). A non-commercial antisecreted Hsp90 $\alpha$ monoclonal antibody, 1G6-D7, was kindly donated by the University of Southern California Keck School of Medicine (USA).

\section{Cell viability assay}

Cell viability was evaluated with a Cell Counting Kit-8 (CCK-8) assay. Briefly, cells were seeded into a 96-well plate at a density of $5 \times 10^{3}$ cells/well and grown to $80 \%$ confluence. After treatments, the medium was replaced with fresh medium containing 10\% CCK-8 reagent. Absorbance at $450 \mathrm{~nm}$ was measured after a 2-hour incubation at $37^{\circ} \mathrm{C}$. Triplicate wells were included for each group.

\section{Detection of MDA content and SOD activity}

Following treatment, supernatants were collected and the levels of lipid peroxidation were determined with a micro-malondialdehyde (MDA) assay reagent kit and an superoxide dismutase (SOD) assay kit (KGT003 and
KGT00150, Keygen Biotech, China) according to the manufacturer's instructions.

\section{Measurement of cellular and mitochondrial ROS}

Intracellular changes in ROS generation were measured with an ROS assay kit (S0033; Beyotime, China). According to the manufacturer's instructions, cells were incubated with $10 \mu \mathrm{M}$ 2',7'-dichlorodihydrofluorescein diacetate (DCFH-DA) in a cell incubator with $5 \% \mathrm{CO}_{2}$ at $37^{\circ} \mathrm{C}$ for $20 \mathrm{~min}$. The fluorescence intensity of the cells was then detected using a flow cytometer.

Mitochondrial ROS activity was measured with MitoSOX Red assay (M36008, Invitrogen). Cells were incubated with $5 \mathrm{mM}$ MitoSOX Red probe for $10 \mathrm{~min}$ at $37^{\circ} \mathrm{C}$. Red fluorescence was determined using an Olympus FV1000 confocal laser scanning microscope (Tokyo, Japan).

\section{Protein extraction and protein expression analysis}

HUVECs were plated in $10 \mathrm{~cm}$ dishes. After treatment, conditioned medium (CM) from the serum-free cultures was collected, centrifuged, and filtered through Millipore Amicon Ultra-4 (50K) column. The total cell lysates were centrifuged at $13000 \times g$ for $15 \mathrm{~min}$ at $4^{\circ} \mathrm{C}$, and the total protein concentration was determined using BCA Protein Assay Kit (Keygen, China).

\section{Immunofluorescence}

Cells were fixed with $4 \%$ paraformaldehyde for $10 \mathrm{~min}$ at room temperature. Permeation was performed by incubating the pretreated cells with ice-cold methanol at $-20^{\circ} \mathrm{C}$ for $15 \mathrm{~min}$. The cells were incubated with primary antibodies $(1: 100)$ at $4^{\circ} \mathrm{C}$ overnight. Images were captured using an Olympus FV1000 confocal laser scanning microscope.

\section{mRNA expression analysis}

Total cell RNA was isolated with RNAiso (Takara, China), and $1000 \mathrm{ng}$ of total RNA were used for reverse transcription with PrimeScript RT Reagent Kit. Real-time quantitative PCR was performed using SYBR Premix Ex Taq and Premix Taq with the indicated primers (online supplemental table 1).

\section{Measurement of 8-0xoG, ET-1, and MCP-1}

Following treatment, cells and supernatants were collected and the levels of DNA damage were measured with an 8-oxoguanine (8-oxoG) ELISA kit (JingKang Bio, China). Endothelial cell injury markers were then detected with a human endothelin 1 (ET-1) ELISA kit (Cusabio, China) and a human monocyte chemotactic protein 1 (MCP-1) ELISA kit (JingKang Bio) according to the manufacturer's instructions.

\section{Cell migration assay}

Twenty-four Transwell inserts with pore sizes of $3 \mu \mathrm{m}$ (Corning, USA) were employed. A total of $10^{6}$ THP-1 monocytes in $200 \mu \mathrm{L}$ of serum-free RPMI-1640 medium were loaded into the upper chamber of each Transwell insert. Then, $600 \mu \mathrm{L}$ of endothelial cell $\mathrm{CM}$ were treated 
with hydrogen peroxide $\left(\mathrm{H}_{2} \mathrm{O}_{2}\right)$ and 17AAG, or RPMI medium was added to the lower chamber. The cells were then allowed to migrate for 8 hours. The cells that migrated across the membrane to the lower chamber were counted under an inverted microscope (Nikon Eclipse TS100, Japan).

\section{Statistical analysis}

All experiments were repeated three times. SPSS V.22.0 was used for statistical processing of the data. Differences between groups were analyzed by one-way analysis of variance, Bonferroni test, Kruskal-Wallis test (K-W test), and $\chi^{2}$ test according to the characteristics of the data. Spearman correlation analysis was used to analyze the correlations of related indexes. A multivariate logistic regression model was used to identify potential independent risk factors. A receiver operating characteristic (ROC) curve was drawn to evaluate the predictive value. Significance level was at $\mathrm{p}<0.05$.

\section{RESULTS \\ Characteristics of the study subjects}

This is a hospital-based, cross-sectional study. The baseline demographic and clinical information of the 103 patients (58 male, $56.3 \%$; 45 female, $43.7 \%$ ) included in this study is displayed in table 1 . All patients were considered to have T2DM as defined by the WHO 1999 criteria. Univariate analysis showed significant differences in age, course, hypertension, hyperlipidemia, family history, C reactive protein (CRP), cholesterol (CHOL), low-density lipoprotein (LDL), white cell count (WCC), and hemoglobin among the three groups $(\mathrm{p}<0.05)$.

Table 1 Baseline characteristics of the study subjects

\begin{tabular}{|c|c|c|c|c|c|}
\hline \multirow[b]{2}{*}{ Parameter } & \multicolumn{3}{|l|}{ Patients } & \multirow[b]{2}{*}{$F\left(\chi^{2}\right)$} & \multirow[b]{2}{*}{$P$ value } \\
\hline & DM & DLEAD & DCLI & & \\
\hline n (\%) & 27 (26.2) & $46(44.7)$ & $30(29.1)$ & & \\
\hline Male/female (n) & $14 / 13$ & $28 / 18$ & $16 / 14$ & 0.715 & 0.699 \\
\hline Age (years) & $44.41 \pm 11.40$ & $57.07 \pm 10.19$ & $64.53 \pm 10.46$ & 26.133 & $<0.001$ \\
\hline BMI $\left(\mathrm{kg} / \mathrm{m}^{2}\right)$ & $22.13 \pm 2.93$ & $23.54 \pm 3.60$ & $23.19 \pm 2.74$ & 1.302 & 0.277 \\
\hline \multicolumn{2}{|l|}{ Course (\%) } & & & 26.036 & $<0.001$ \\
\hline$<5$ years & $23(85.2)$ & 15 (32.6) & $8(26.7)$ & & \\
\hline $5-10$ years & $2(7.4)$ & $11(23.9)$ & 4 (13.3) & & \\
\hline$\geq 10$ years & $2(7.4)$ & 18 (39.1) & $17(56.7)$ & & \\
\hline Smoking (\%) & 7 (25.9) & $15(32.6)$ & $6(20.0)$ & 1.145 & 0.564 \\
\hline Current & 5 & 14 & 5 & & \\
\hline Former & 2 & 1 & 1 & & \\
\hline Never & 20 & 31 & 24 & & \\
\hline Hypertension (\%) & 7 (25.9) & $19(41.3)$ & $18(60.0)$ & 8.314 & 0.016 \\
\hline Hyperlipidemia (\%) & $6(22.2)$ & $23(50.0)$ & $13(43.3)$ & 6.264 & 0.044 \\
\hline Family history (\%) & $3(11.1)$ & 19 (41.3) & $5(16.7)$ & 9.936 & 0.007 \\
\hline 2hPBG (mM) & $10.51 \pm 4.41$ & $11.67 \pm 3.91$ & $9.75 \pm 5.12$ & 1.616 & 0.205 \\
\hline GLU (mM) & $7.65(5.23-14.46)$ & $7.11(4.92-10.13)$ & 9.41 (6.39-14.97) & 2.699 & 0.259 \\
\hline HbA1c (mmol/mol) & $9.70(7.21-12.41)$ & $9.25(8.20-11.20)$ & $7.80(7.10-9.50)$ & 4.205 & 0.122 \\
\hline CRP (mg/L) & $1.12(0.57-5.66)$ & $2.40(0.85-7.54)$ & 21.35 (2.63-62.07) & 12.601 & 0.002 \\
\hline $\mathrm{TG}(\mathrm{mM})$ & $1.40(1.06-2.53)$ & $1.57(0.94-2.44)$ & $1.61(1.28-2.77)$ & 2.388 & 0.303 \\
\hline $\mathrm{CHOL}(\mathrm{mM})$ & $4.87(3.91-5.55)$ & $4.22(3.22-5.24)$ & $3.77(2.93-4.58)$ & 7.465 & 0.024 \\
\hline HDL-C (mM) & $1.09(0.82-1.30)$ & $0.94(0.76-1.17)$ & $0.84(0.72-0.97)$ & 5.832 & 0.054 \\
\hline LDL-C (mM) & $3.09 \pm 0.88$ & $2.67 \pm 0.94$ & $2.43 \pm 1.05$ & 3.237 & 0.044 \\
\hline WCC $\left(\times 10^{9} / \mathrm{L}\right)$ & $6.66(5.31-9.02)$ & $7.61(6.50-9.50)$ & $8.74(7.21-11.71)$ & 7.171 & 0.028 \\
\hline $\mathrm{Hb}(\mathrm{g} / \mathrm{L})$ & $138.6(128.5-145.5)$ & $127.5(113.0-143.0)$ & $106.0(85.0-118.5)$ & 21.340 & $<0.001$ \\
\hline $\begin{array}{l}\text { Data are mean } \pm \text { SD } \\
\text { BMI, body mass ind } \\
\text { lower extremity arte } \\
\text { high-density lipopro } \\
\text { TG, triglyceride; WC }\end{array}$ & $\begin{array}{l}\text { ian (IQR). } \\
\text { OL, cholesterol; CRP } \\
\text { ease; DM, diabetes n } \\
\text { olesterol; 2hPBG, 2-ץ } \\
\text { te cell count. }\end{array}$ & $\begin{array}{l}\text {; } \text {; GLU, glucose; Hb, } \\
\text { ostprandial blood glu }\end{array}$ & $\begin{array}{l}\text { etic critical limb isc } \\
\text { oglobin; HbA1c, he } \\
\text { e; LDL-C, low-dens }\end{array}$ & $\begin{array}{l}\text { a; DLEA } \\
\text { lobin A1 } \\
\text { ooproteir }\end{array}$ & $\begin{array}{l}\text { abetic } \\
\text { DL-C, } \\
\text { lesterol; }\end{array}$ \\
\hline
\end{tabular}


Comparison and correlation analyses of serum levels of MDA, Hsp90 $\alpha$, Hsp90ß, WCC, and CRP in the study subjects

The levels of MDA, Hsp90 $\alpha$, and Hsp90 $\beta$ in the three groups are shown in figure 1A-C. In pairwise comparisons, the levels of the above indicators were significantly higher in patients with DLEAD or DCLI than in patients with DM. The results showed that patients with T2DM were characterized by a state of continuous and chronic oxidative stress. The relationships of Hsp90 $\alpha$ and Hsp90 $\beta$ with WCC, CRP, and MDA levels in the study subjects are shown in figure 1D-I. Pearson's correlation analysis showed that there were significant correlations between Hsp90 $\alpha$ and MDA levels $(r=0.233, p=0.018)$.

\section{Multivariate logistic regression model of risks associated with diabetic vascular disease}

The results of the collinearity analysis of independent variables showed that triglyceride and $\mathrm{CHOL}$ were collinear (online supplemental table 2). The clinical variables with statistical significance that were identified in the univariate logistic regression analysis (online supplemental tables 3 and 4) were included in the multivariate logistic regression analysis (figure 2A). As depicted, age, Hsp90 $\alpha$, course, and family history were independent risk factors for DLEAD. Moreover, age, Hsp90 $\alpha$, Hsp90 $\beta$, and course were independent risk factors for DCLI.

\section{Diagnostic efficacy of Hsp90 $\alpha$ and Hsp90 $\beta$ for DLEAD}

ROC curve analysis was conducted to assess the diagnostic efficacy of Hsp90 $\alpha$ and Hsp90 $\beta$ for DLEAD (figure 2B). Hsp90 $\alpha$ showed better diagnostic performance in the DLEAD group than in the DM group. The area under the curve (AUC) of Hsp90 $\alpha$ was 0.701 (61.84\% sensitivity and $77.78 \%$ specificity) and the cut-off was 263.88 (Youden index: 0.396), while the AUC of Hsp90 $\beta$ was 0.660 (31.58\% sensitivity and $96.29 \%$ specificity) and the cut-off was 325.88 (Youden index: 0.279).

\section{Histopathological sections}

Both inflammatory cell infiltration and elevated Hsp90 $\alpha$ expression were present. Tissue sections prepared from human atherosclerotic lesions were subjected to HE staining (figure 2C,E) and immunohistochemistry (figure 2D,F). Inflammatory cells infiltrated the intima heavily in patients with DCLI. Hsp90 $\alpha$ was abundantly expressed in the endothelium and smooth muscle. In addition, the expression area of $\mathrm{Hsp} 90 \alpha$ was consistent with the area of inflammatory infiltration.

\section{Vascular endothelial cell model of oxidative injury in vitro}

The results of $\mathrm{H}_{2} \mathrm{O}_{2}$ concentration screening (figure 3A) indicated that after treatment with $300 \mu \mathrm{M} \mathrm{H}_{2} \mathrm{O}_{2}$ for 24 hours, the cell survival rate was nearly $80 \%$. HUVECs exposed to $\mathrm{H}_{2} \mathrm{O}_{2}$ at $200 \mu \mathrm{M}$ and $300 \mu \mathrm{M}$ exhibited significantly different MDA contents (figure 3B) and SOD activities (figure 3C) than control cells. Cellular ROS (figure 3D) and mitochondrial ROS detection (figure 3E) indicated that the ROS levels of HUVECs treated with $300 \mu \mathrm{M} \mathrm{H}_{2} \mathrm{O}_{2}$ for 24 hours were increased. At the same time, the expression of the DNA damage marker 8-oxoG and endothelial cell damage factor ET-1 and MCP-1 was increased (figure $3 \mathrm{~F}-\mathrm{H}$ ). These results suggest that 300 $\mu \mathrm{M} \mathrm{H}_{2} \mathrm{O}_{2}$ treatment for 24 hours can successfully establish an oxidative stress injury model in endothelial cells.

\section{Increased eHsp90 secretion in the vascular endothelial injury} model

HUVECs were treated with $\mathrm{H}_{2} \mathrm{O}_{2}$ at a range of doses. eHsp90 $\alpha$ and eHsp90 $\beta$ secretion increased, but the total amount of intracellular Hsp90 did not change significantly (figure 3I). After $\mathrm{H}_{2} \mathrm{O}_{2}$ treatment, the total amount of eHsp90 $\alpha$ and eHsp90 $\beta$ from HUVECs was the highest at 24 hours (figure 3J). Treatment with $\mathrm{H}_{2} \mathrm{O}_{2}$ and 17AAG alone or in combination significantly increased the eHsp90 of endothelial cells. In addition, $\mathrm{H}_{2} \mathrm{O}_{2}$ had little effect on the expression of Hsp90AA1 and Hsp90AB1 (figure 3K,L). The immunofluorescence results (figure 3M) showed that Hsp90 $\alpha$ localization shifted with treatment; specifically, the fluorescence at the cell edges increased, suggesting that the expression of Hsp90 $\alpha$ in the membrane and periphery may have increased.

\section{eHsp90 $\alpha$ enhances the inflammatory injury state of endothelial cells}

To explore the specific biological role of eHsp90 in the inflammatory injury model, endothelial cells were treated with human recombinant (hr)Hsp90 protein to assess the expression of related functional indicators. The results showed that eHsp90 $\alpha$ increased the expression of ET-1 and MCP-1 in endothelial cell culture medium (figure 4A,B). However, the effect of eHsp90 $\beta$ on endothelial cell dysfunction was not significant. Under oxidative stress, 17AAG and 1G6-D7 were added to inhibit eHsp90 $\alpha$ and the expression of ET-1 decreased, suggesting that endothelial cell functional damage was alleviated (figure 4C).

\section{eHsp90 recruits monocytes through LRP1 receptor activation} of p-Akt kinase

To study the effect of chronic oxidative stress on the development and progression of AS, we next examined the effect of endothelial cell CM on monocytes. Compared with the control medium, $\mathrm{H}_{2} \mathrm{O}_{2}$-treated $\mathrm{CM}$ induced THP-1 migration. CM from endothelial cells treated with 17AAG alone or $\mathrm{H}_{2} \mathrm{O}_{2}$ in combination exhibited a significantly decreased ability to induce THP-1 migration (figure 4D). We observed that hrHsp90 $\alpha$ exposure increased the number of THP-1 cells that migrated to the lower chamber. The chemotactic effect of hrHsp90 $\beta$ on THP-1 monocytes was not obvious. We used 1G6-D7 to identify the specificity of Hsp90 $\alpha$ for chemotactic THP-1 monocytes. The results showed that the chemotactic ability of monocytes was weakened by the addition of 17AAG or 1G6-D7 (figure 4E).

Next, we treated THP-1 cells with hrHsp90 $\alpha$ and Western blotting showed that the LRP1 protein content was significantly elevated in the treated cells. To confirm 
A

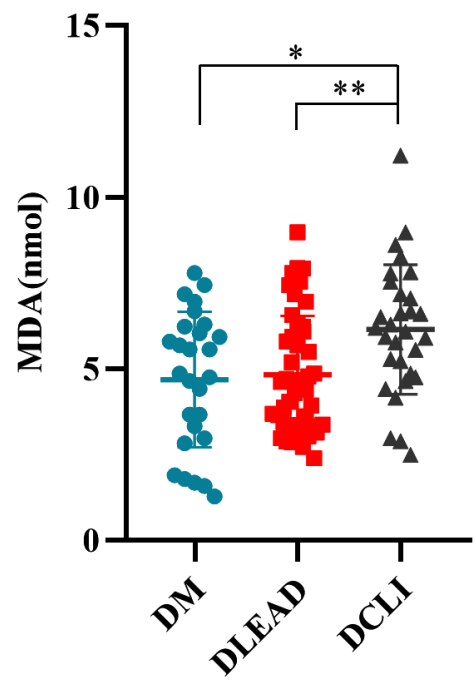

D

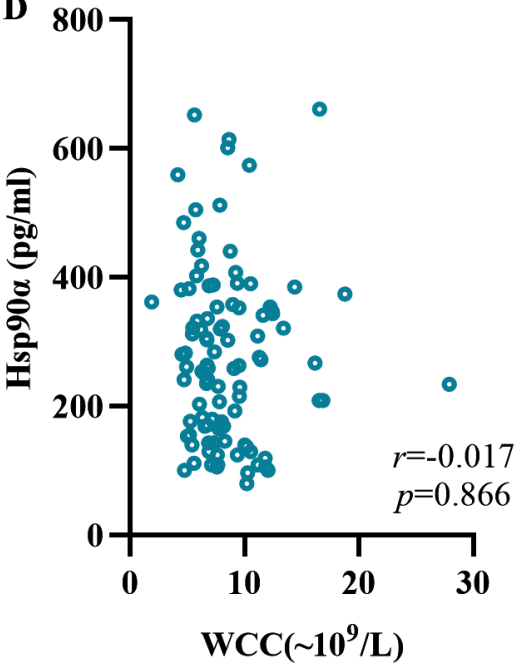

B

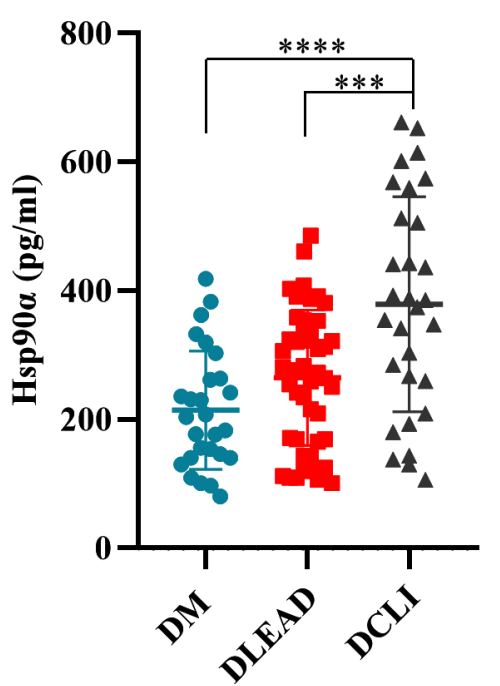

$\mathbf{E}$

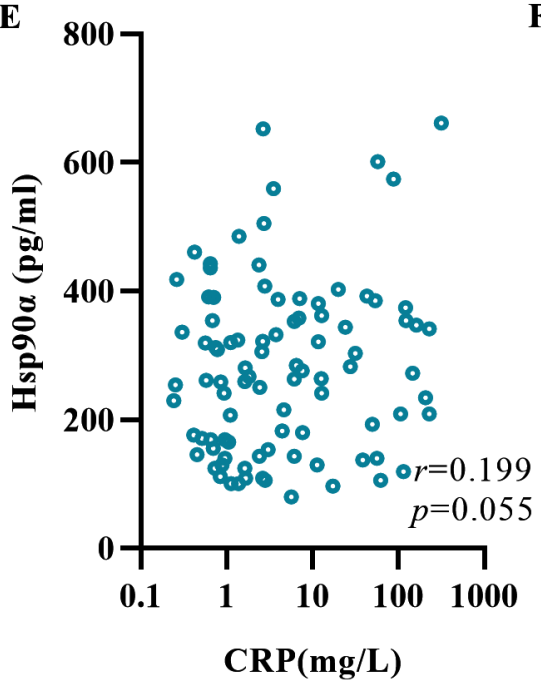

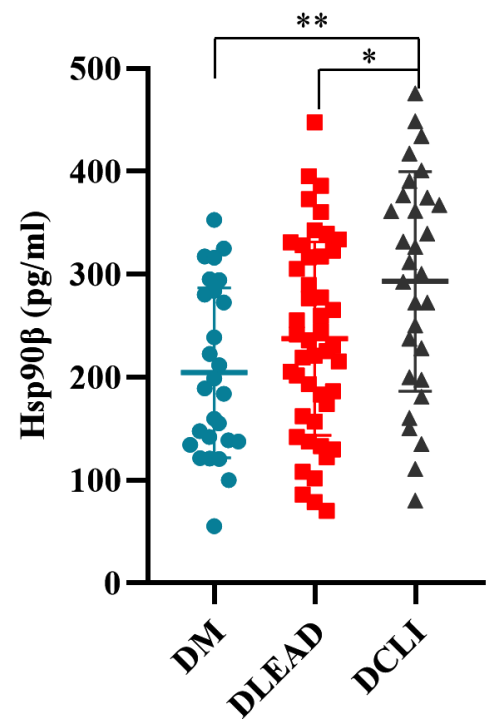

$\mathbf{F}$

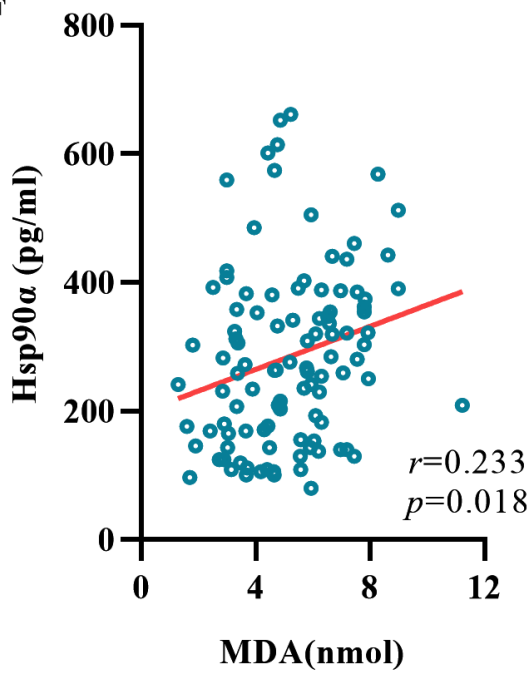

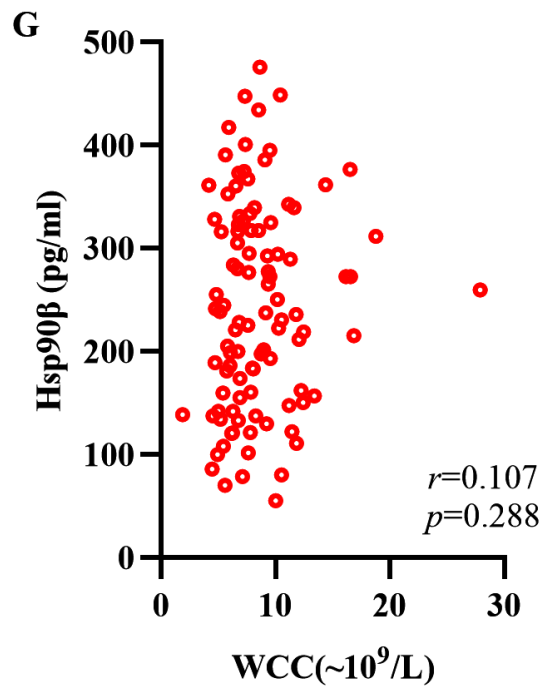
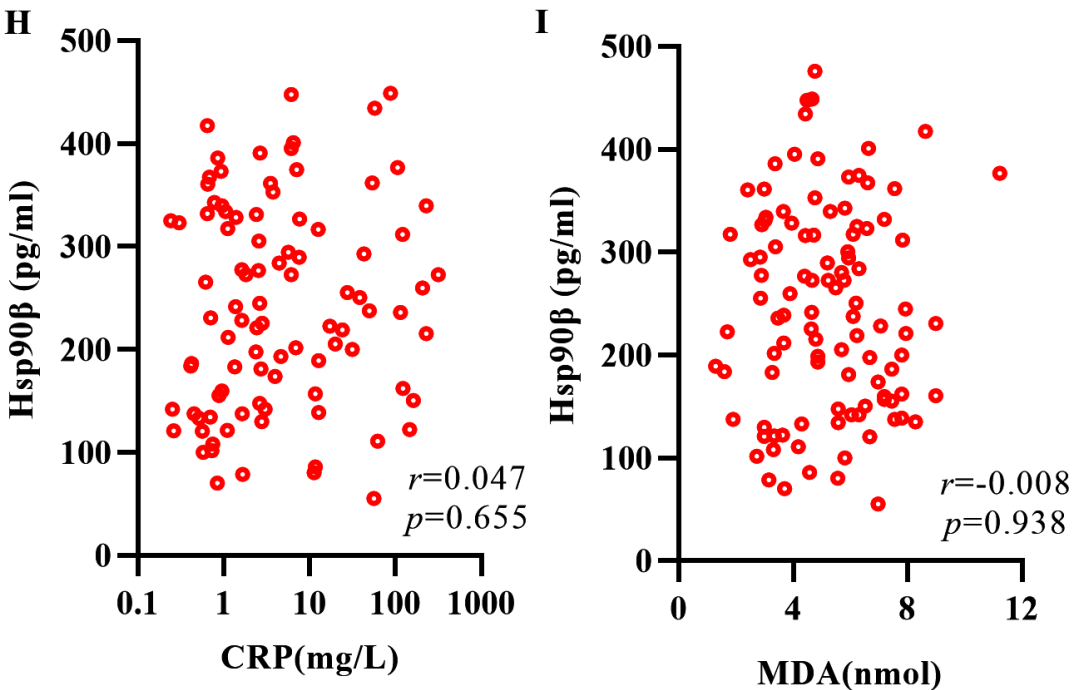

Figure 1 Comparison and correlation analyses of serum levels of MDA, Hsp90 $\alpha$, Hsp90ß, WCC, and CRP in the study subjects. Serum MDA (A), Hsp90 $\alpha(B)$, and $H \operatorname{sp} 90 \beta$ (C) levels were measured in the different groups. ${ }^{*} P<0.05,{ }^{* *} P<0.01$, ${ }^{\star * \star} \mathrm{P}<0.001,{ }^{\star \star \star \star} \mathrm{P}<0.0001$ versus the DM or the DLEAD group. Correlation between Hsp90 $\alpha$ (D-F) and Hsp90 (G-I) and WCC, CRP, and MDA levels in serum samples. Pearson's coefficient tests were conducted to calculate statistical significance. CRP, C reactive protein; DCLI, diabetic critical limb ischemia; DLEAD, diabetic lower extremity arterial disease; DM, diabetes mellitus; Hsp90, heat shock protein 90; MDA, malondialdehyd; WCC, white cell count. 

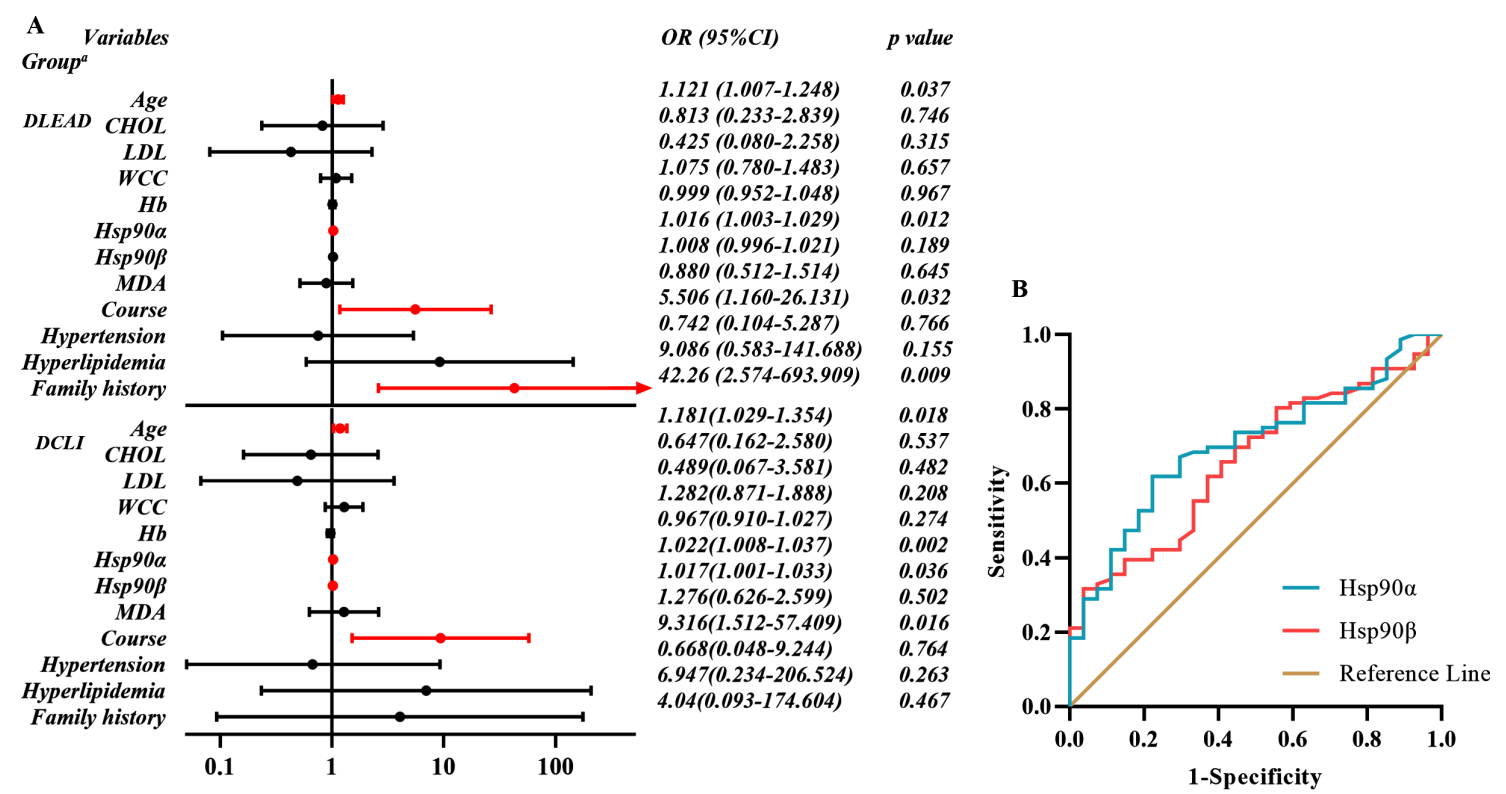

a:The reference category is $\mathrm{DM}$

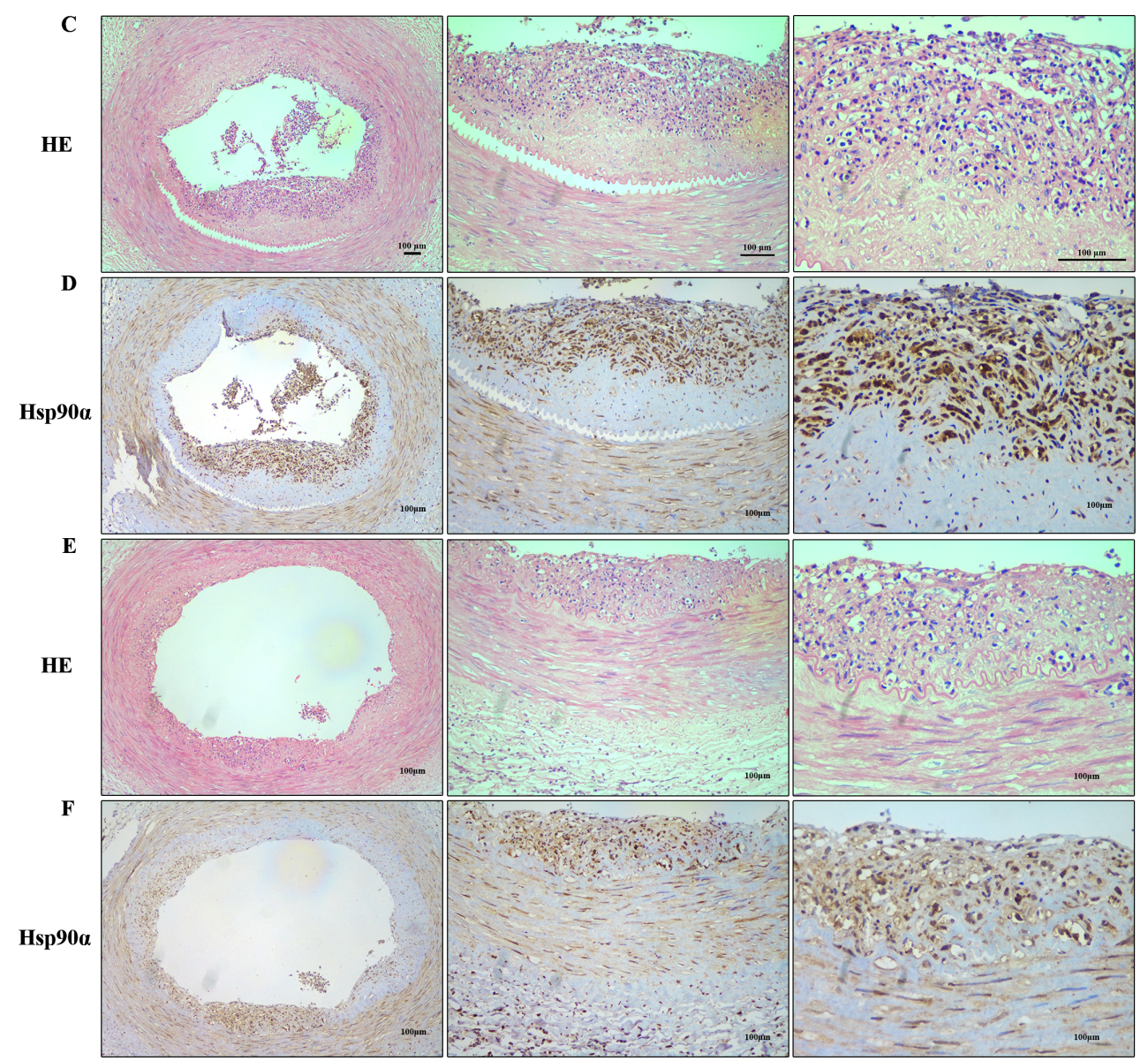

Figure 2 Multivariate logistic regression model and diagnostic efficacy of Hsp90 $\alpha$ and Hsp90ß for DLEAD. Histopathological changes in blood vessels. Multivariate logistic regression analysis (A): a forest plot obtained from a multiple logistic regression model as OR with $95 \% \mathrm{Cl}$. Comparing patients with DLEAD and DM, age, Hsp90 $\alpha$, course, and family history were independent risk factors for the development of DLEAD. Comparing patients with DCLI and DM, age, Hsp90 $\alpha, \mathrm{Hsp} 90 \beta$, and course were independent risk factors for DCLI. Receiver operating characteristic analysis of the diagnostic efficacy of Hsp90 $\alpha$ and Hsp90 $\beta$ for DM and DLEAD (B). Diagnostic ability to distinguish patients with DLEAD from patients with DM. HE staining (C and E) and immunohistochemistry (D and F) (40x, 100x, 200x) of Hsp90 $\alpha$ in the blood vessels of patients with DCLI undergoing partial amputation $(n=3)$. CHOL, cholesterol; $D C L I$, diabetic critical limb ischemia; DLEAD, diabetic lower extremity arterial disease; DM, diabetes mellitus; Hb, hemoglobin; Hsp90, heat shock protein 90; LDL, low-density lipoprotein; MDA, malondialdehyd; WCC, white cell count. 

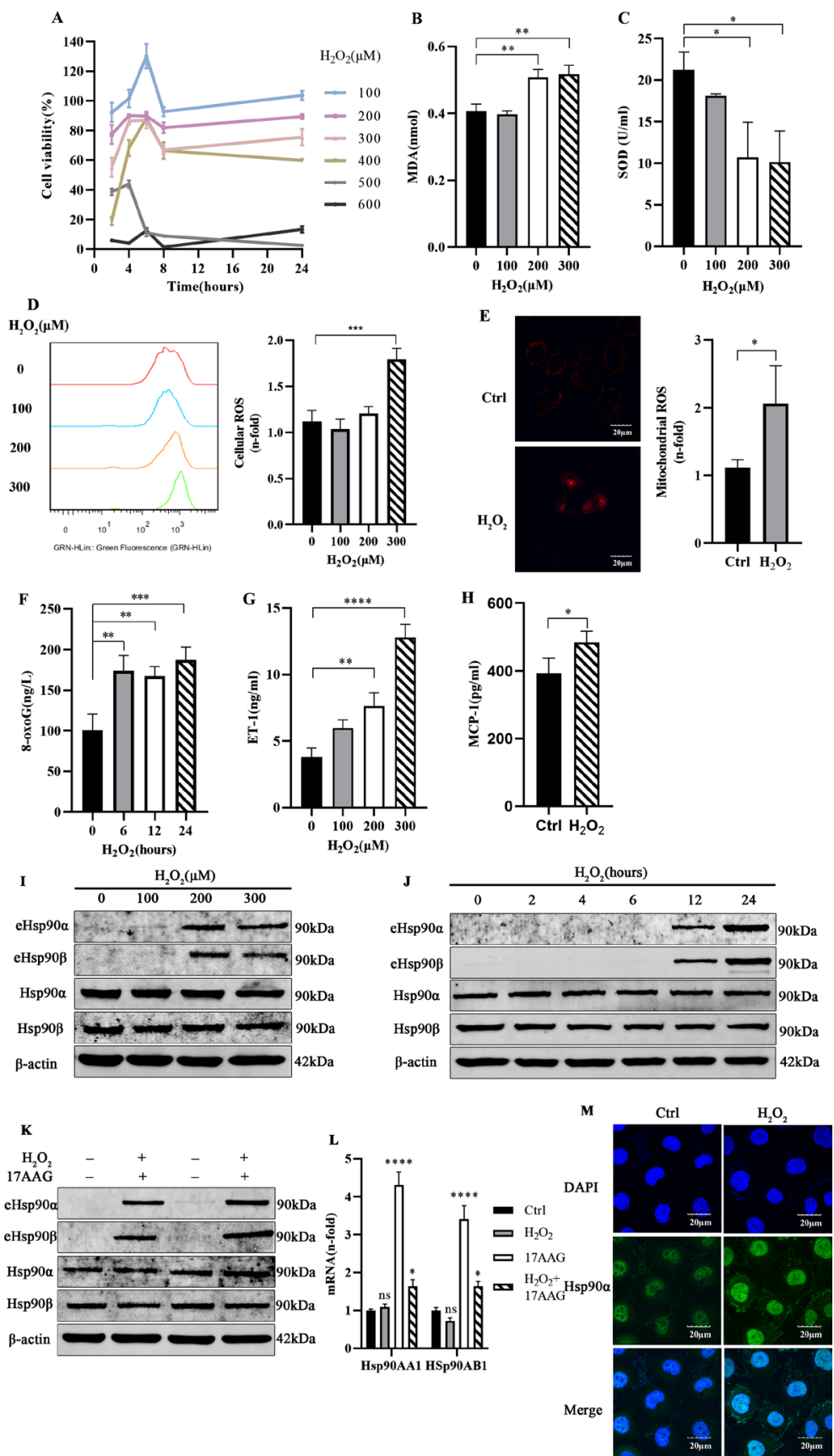

Figure 3 Increased eHsp90 secretion in a vascular endothelial cell model of oxidative injury in vitro. A CCK-8 assay (A) was used to detect cell viability in HUVECs treated with different concentrations of $\mathrm{H}_{2} \mathrm{O}_{2}$ for 2, 4, 6, 8, and 24 hours ( $\mathrm{n}=3$ ). The levels of MDA (B) and SOD (C) were measured with assay kits $(n=3)$. HUVECs were treated with $\mathrm{H}_{2} \mathrm{O}_{2}(100 \mu \mathrm{M}, 200 \mu \mathrm{M}$, and $300 \mu \mathrm{M}$ ) for 24 hours, and then the intracellular levels of ROS (D), mitochondrial ROS (E), and 8-oxoG (F) and the extracellular levels of ET-1 $(\mathrm{G})$ and MCP-1 $(\mathrm{H})$ were detected $(n=3)$. (I) Western blot analysis concentrated medium and total cell extracts from HUVECs cultured with the indicated concentration of $\mathrm{H}_{2} \mathrm{O}_{2}$. ImageJ software was used to determine the relative intensities of extracellular and intracellular $\mathrm{Hsp} 90 \alpha$ and $\mathrm{Hsp} 90 \beta$ bands ( $\mathrm{n}=3$ ). (J) Extracellular and intracellular $\mathrm{Hsp} 90 \alpha$ and $\mathrm{Hsp} 90 \beta$ expressions were measured after $\mathrm{H}_{2} \mathrm{O}_{2}$ stimulation for different durations $(n=3)$. (K) Western blot analysis was performed to assess the expression of related proteins in HUVECs pretreated with 17AAG and then exposed to $\mathrm{H}_{2} \mathrm{O}_{2}(n=3)$. (L) qPCR was employed to observe the respective $\mathrm{Hsp} 90 \alpha$ and $\mathrm{Hsp} 90 \beta$ mRNA levels after HUVECs were stimulated with $\mathrm{H}_{2} \mathrm{O}_{2}$ and/or $17 \mathrm{AAG}$ for 24 hours ( $n=3$ ). (M) Representative confocal images of Hsp90 $\alpha$ subunit localization in endothelial cells after 24 hours of $\mathrm{H}_{2} \mathrm{O}_{2}$ stimulation are shown $(n=3)$. All data represent mean \pm SD of three biological replicates. Differences between groups were analyzed by one-way ANOVA and the Dunnett test, according to the data features. ${ }^{*} \mathrm{P}<0.05,{ }^{* \star} \mathrm{P}<0.01,{ }^{* \star} \mathrm{P}<0.001{ }^{* * * *} \mathrm{P}<0.0001$ versus control. 17AAG,17-allyamino-17-demethoxygeldanamycin; ANOVA, analysis of variance; CCK-8, Cell Counting Kit8; Ctrl, control; DAPI, 4',6-diamidino-2-phenylindole; eHsp90, extracellular heat shock protein 90; $\mathrm{ET}^{-1}$, endothelin 1; $\mathrm{H}_{2} \mathrm{O}_{2}$, hydrogen peroxide; Hsp90, heat shock protein 90; HUVECs, human umbilical vein endothelial cells; MCP-1, monocyte chemotactic protein 1; MDA, malondialdehyd; mRNA, messenger RNA; 8-oxoG, 8-oxoguanine; qPCR, quantitative real-time PCR; ROS, reactive oxygen species; SOD, superoxide dismutase. 

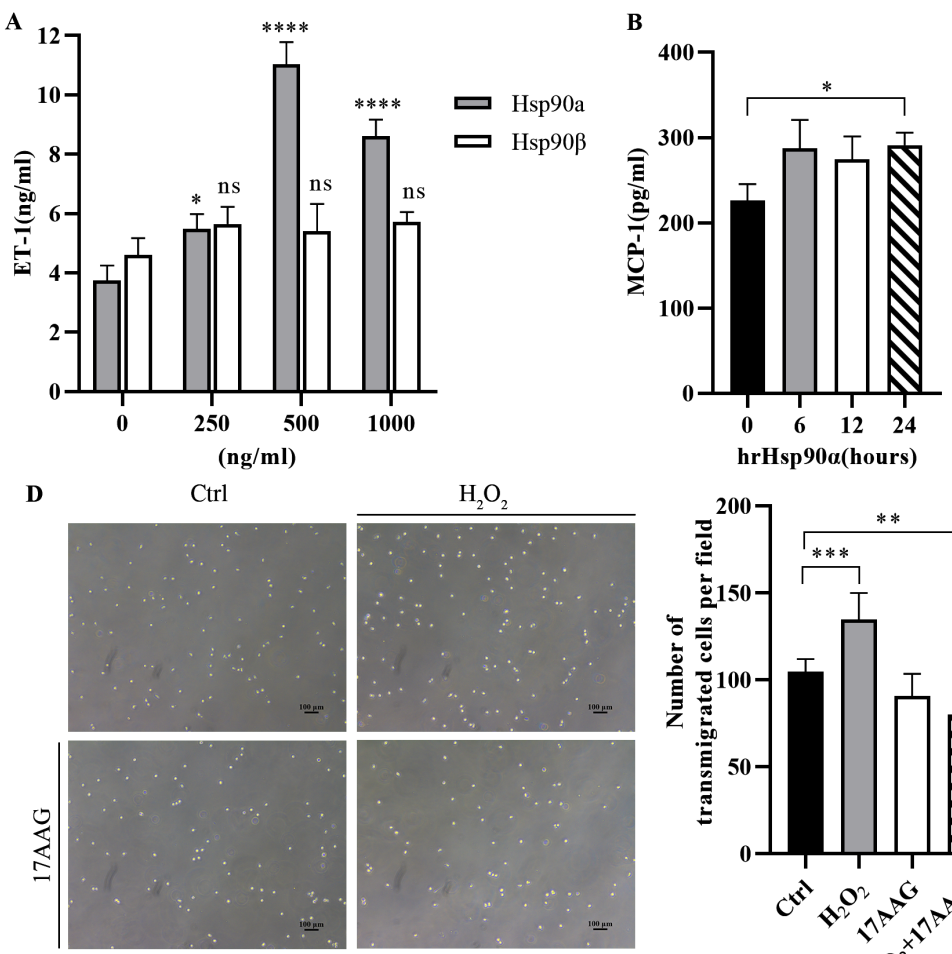

E Ctrl
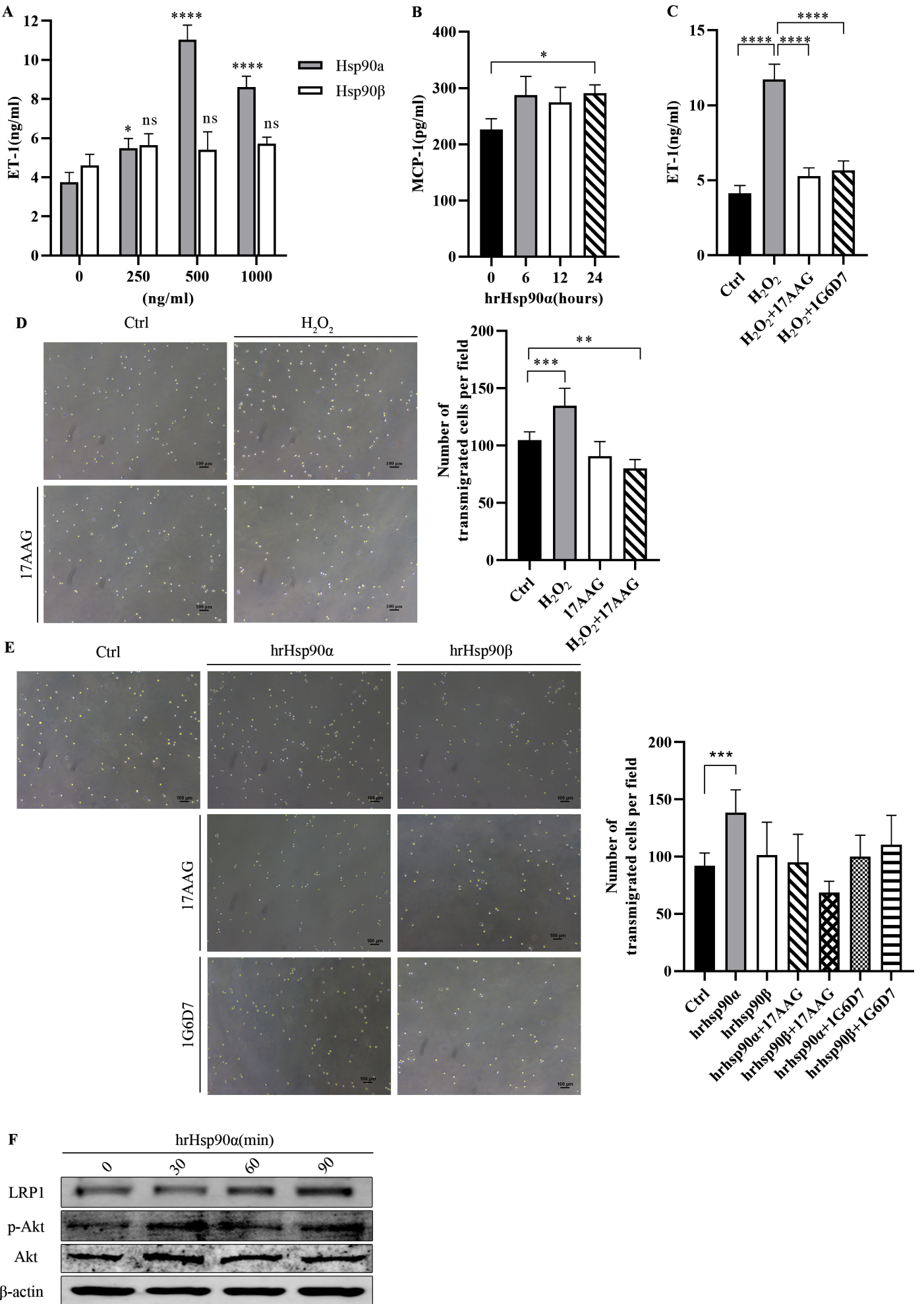

Figure 4 eHsp90 $\alpha$ enhanced the inflammatory injury state of endothelial cells and recruited monocytes through LRP1 receptors. Extracellular ET-1 (A) and MCP-1 (B) expressions were measured after hrHsp90 $\alpha$ stimulation at different concentrations and durations $(n=3)$. The expression of ET-1 (C) in endothelial cell-CM treated with $\mathrm{H}_{2} \mathrm{O}_{2}$ after 17AAG or 1G6D7 pretreatment $(n=3)$. Representative images with quantification of the results for a THP-1 cell Transwell migration assay in the presence of $\mathrm{H}_{2} \mathrm{O}_{2}$-treated and/or 17AAG-treated endothelial cell CM (D) and different reagents (E) $(n=5)$. LRP1 and p-Akt expressions $(F)$ were measured after hrHsp90 $\alpha$ stimulation for different durations $(n=3)$. All data represent mean $\pm S D$ of three biological replicates. Differences between groups were analyzed by one-way ANOVA and the Dunnett test, according to the data features. ${ }^{\star} \mathrm{P}<0.05,{ }^{\star \star} \mathrm{P}<0.01,{ }^{\star * \star} \mathrm{P}<0.001,{ }^{* \star \star *} \mathrm{P}<0.0001$ versus control. $17 \mathrm{AAG}, 17$-allyamino-17-demethoxygeldanamycin; ANOVA, analysis of variance; CM, conditioned medium; Ctrl, control; eHsp90, extracellular Hsp90; ET-1, endothelin 1; $\mathrm{H}_{2} \mathrm{O}_{2}$, hydrogen peroxide; hrHsp90, human recombinant Hsp90; Hsp90, heat shock protein 90; LRP1, low-denisity lipoprotein receptor-related protein 1; MCP-1, monocyte chemotactic protein 1. 
the involvement of the eHsp90 $\alpha$-Akt pathway, we determined that stimulation with eHsp90 $\alpha$ induced timedependent activation of p-Akt (figure 4F).

\section{DISCUSSION}

In our study, we clarified the relationships of oxidative stress with serum Hsp90 levels in patients with diabetes. We propose that serum Hsp90 $\alpha$ has reference value for early diagnosis of DLEAD, and our findings indicate that low-dose and long-term ROS exposure can increase eHsp90 secretion from endothelial cells. eHsp90 $\alpha$ acts as a chemokine to induce THP-1 cell migration, which may result from a compensatory response of early inflammation and oxidative stress in AS, initiating the atherosclerotic process (online supplemental figure 1 ).

The incidence and mortality rates of atherosclerotic cardiovascular disease are significantly higher in patients with diabetes than in those without. ${ }^{14}$ Of patients with T2DM, $50 \%$ have complications at the time of diagnosis. ${ }^{15}$ However, fewer than $10 \%$ of patients have typical clinical symptoms and the lack of effective treatments affects patients' prognoses. ${ }^{16}$ Recent studies have reported several potential serum markers for screening of diabetic vascular complications, such as serum fibroblast growth factor $23,{ }^{17}$ serum sclerostin, ${ }^{18}$ and circulating Hsp27. ${ }^{19}$ In addition, heat shock proteins (HSPs) can be transported to the plasma membrane and released extracellularly, resulting in detectable levels of HSP in the blood. This finding has prompted clinical studies exploring the potential use of HSP and anti-HSP antibodies as serum biomarkers for DM complications. ${ }^{20}$ Available data suggest that circulating Hsp27, ${ }^{21} \mathrm{Hsp} 60,{ }^{22} \mathrm{Hsp} 70,{ }^{23}$ and anti-HSP levels may be used as biomarkers for diabetic vascular disease. In type 1 diabetes mellitus, elevated serum Hsp90 levels have been found to be related to cellular autoimmunity in children. ${ }^{24}$ New findings confirmed the role of Hsp90 as a putative autoantigen triggering inflammation within human carotid atherosclerotic plaques. ${ }^{25}$ However, there have been no studies on the relationships between eHsp90 and T2DM macrovascular complications. Most of the previous studies focused on the risk factors for LEAD, while there was no clear study on the process from diabetes to vascular disease complications. Therefore, we sought to investigate whether there is an indicator that can be included in primary prevention strategies that has reference value for early prediction. Numerous studies have reported that patients with DM have chronic inflammation, but now many inflammation indicators are closely related to acute infection, such as CRP and procalcitonin (PCT) ${ }^{26}$; thus, these indicators may not truly reflect chronic inflammation. Serological studies have found that the degree of oxidative stress in patients with diabetes is cumulative and that circulating Hsp90 $\alpha$ may reflect a patient's oxidative stress state. Predictive analysis indicated that serum Hsp90 $\alpha$ shows better performance in the initial diagnosis of LEAD in patients with early DM than in patients with diabetes without atherosclerotic changes. However, the number of clinical samples included in this study was still insufficient and no healthy control group was found, so the results could only be limited to patients with diabetes and could not be further extended. The medical treatment of patients was not included in the analysis, so the influence of drugs on relevant indicators could not be excluded. In subsequent studies, we will further improve relevant information to determine whether $\mathrm{Hsp} 90 \alpha$ can be used as a direct risk factor.

It is generally believed that abnormal glucose metabolism damages the arterial endothelial barrier while increasing platelet and inflammatory cell aggregation, which increases local oxidative stress levels. Destruction of the barrier function of vascular endothelial cells is a crucial initial step in this process. ${ }^{27}$ Oxidative stress is a potential mechanism for the development of endothelial cell dysfunction that is common to all risk factors. ${ }^{28}$ Previous research has shown that Hsp90 promotes the progression of AS through several mechanisms. oxidized low density lipoprotein (oxLDL) enhanced endothelial nitric oxide synthases (eNOS) association with Hsp90 and impaired endothelium-dependent vasodilation. ${ }^{29}$ However, statins repress human Dendritic Cells (DC) maturation induced by oxLDL, and repress an atherogenic HSP profile and promote the induction of $\mathrm{T}$ regulatory cells. ${ }^{30} \mathrm{Hsp} 60$ has also been found to induce inflammatory cell activation. ${ }^{31}$ Lentivirus-mediated short hairpin RNA (shRNA) knockdown of Hsp60 and Hsp90 in DCs attenuated the effects of human group X-secreted phospholipase A2 (LDLx) on dendritic cell proliferation. ${ }^{32}$ However, existing studies have focused on the role of Hsp90 in cells and have not clearly distinguished between Hsp90 $\alpha$ and Hsp90 $\beta$ and the possible mechanism of action of eHsp90. Next, we verified cytologically that oxidative stress upregulates the expression of eHsp90 in HUVECs and that this process is not accompanied by an increase in Hsp90 gene expression or a decrease in intracellular protein expression. These findings are in contrast to those of a study by Profumo $e t a l l^{33}$ in which oxidative stress upregulates Hsp90 expression on the surfaces of endothelial cells and reduces Hsp90 secretion. There may be a link between the two findings. The expression of eHsp90 may be related to the duration of oxidative stress in cells. After a short (2 hours or 4 hours) treatment, no change in the amount of eHsp90 was observed in the cell culture medium. Previous studies have rarely used indicators to simultaneously measure oxidative stress at both the population and cell levels or used such indicators as references. In our study, we used MDA to measure the oxidative stress state of the population and found that MDA levels were lower in cells after $\mathrm{H}_{2} \mathrm{O}_{2}$ treatment than in patient serum. These findings suggest that endothelial cells under low-concentration $\mathrm{H}_{2} \mathrm{O}_{2}$ treatment exhibit increased expression of eHsp90, which can stimulate oxidative stress in humans.

AS is a lipid-driven inflammatory disease of the arterial intima. The balance of proinflammatory and 
anti-inflammatory mechanisms determines the final clinical outcome, which is characterized by gradual accumulation of lipids and inflammatory cells. ${ }^{34}$ Two chemotactic processes are involved in AS: monocyte chemotaxis and smooth muscle fibroblast chemotaxis. Circulating leukocytes adhere to and migrate through the endothelial wall to the vascular smooth muscle layer of the intimal membrane. ${ }^{35}$ The migration of monocytes is an early disease indicator. Ambade $e t a l^{36}$ found that the extracellular vesicles (EVs) of mice with alcoholic liver disease can induce macrophage activation through Hsp90. In addition, colocalization of inflammatory cells and $H$ sp90 $\alpha$ was found in patient tissue samples, so we hypothesized that there may be a connection between Hsp90 $\alpha$ and inflammatory damage. The results showed that eHsp90 $\alpha$ could promote endothelial cell dysfunction and the release of inflammatory cytokines. CM and eHsp90 $\alpha$ could promote monocyte migration and initiate the inflammatory process of AS. When we used recombinant Hsp90 $\alpha$ to treat monocytes, we observed increased expression of LRP1 in a short period of time, which activated p-Akt, thereby promoting monocyte migration. Our study provides in vitro evidence of the key pathological role of eHsp90 $\alpha$ in the control of diabetic vascular complications. This study did not go deep into the cell signaling mechanisms. In the future, we will study the pathway mechanism by knocking down or overexpressing genes, using pathway inhibitors and other means.

For the treatment of AS, there is no specific drug at present and it mainly focuses on the comprehensive management of patients, lowering blood glucose and blood lipids, etc. In the future, targeted therapies targeting different cell types in vivo, such as monocytemacrophage lines ${ }^{37}$ and regulating VSMC phenotypic switching, ${ }^{38}$ could be considered. Another study found that the Hsp90 inhibitor 17-DMAG attenuates oxidative stress in experimental AS. ${ }^{39}$ This suggests that inhibition of Hsp90 alleviates the progression of AS. Based on our results, new drugs targeting eHsp90 for its proinflammatory properties could be developed in the future.

The study focused on serum Hsp90 $\alpha$, a substance strongly associated with oxidative stress in diabetic AS. This research enriches the understanding of the mechanism and biological function of eHsp90 $\alpha$. Through a clinical study, we combined clinical findings with novel functions of eHsp90 $\alpha$ protein. However, as a singlecenter clinical study, serological results are unrepresentative. There may be admission rate bias, no response bias, etc. Due to selection bias, the research results could not reflect the real connection between a certain factor and the disease. The exploratory study of eHsp90 $\alpha$ lacks specific functional area validation. In summary, the current study shows that eHsp90 $\alpha$ participates in the inflammatory process of AS and is expected to become a promising new target for disease prediction and for treatment to slow the progression of AS.
Author affiliations

${ }^{1}$ Department of Occupational Health and Medicine, School of Public Health, Southern Medical University, Guangzhou, China

${ }^{2}$ Department of Endocrinology and Metabolism, NanFang Hospital, Southern Medical University, Guangzhou, Guangdong, China

${ }^{3}$ Department of Respiratory and Critical Care Medicine, Nanfang Hospital, Southern Medical University, Guangzhou, Guangdong, China

${ }^{4}$ Department of Burns, Nanfang Hospital, Southern Medical University, Guangzhou, Guangdong, China

${ }^{5}$ Department of Dermatology and the Norris Comprehensive Cancer Center, Keck Medical Centre, University of Southern California, Los Angeles, California, USA

Acknowledgements The authors thank all patients who participated in the study.

Contributors XD, CM, and HD performed the experiments, analyzed the data, and wrote the manuscript. SZ, HZ, and WT analyzed the data. LH and AH collected specimens. JL and JH contributed to the discussion. WL, FZ, and MZ designed the experiment and reviewed the manuscript. MZ is the guarantor of this work and, as such, had full access to all the data in the study and takes responsibility for the integrity of the data and the accuracy of the data analysis.

Funding This work was supported by the National Natural Science Foundation of China (NSFC) (no. 81600648, 82170840 to MZ; no. 81971783 to FZ; and no. 81870058 to HD). And this work was supported by the Outstanding Youth Cultivation Program of Nanfang Hospital, Southern Medical University (no.2021J003 to MZ)

Competing interests None declared.

\section{Patient consent for publication Not required}

Ethics approval This study involves human participants and was designed and implemented in accordance with the Declaration of Helsinki (2013) and approved by the Ethics Committee of Nanfang Hospital (NFEC-2020-268). Participants gave informed consent to participate in the study before taking part.

Provenance and peer review Not commissioned; externally peer reviewed.

Data availability statement No data are available. The data generated and analyzed during the current study are available from the corresponding author upon reasonable request.

Supplemental material This content has been supplied by the author(s). It has not been vetted by BMJ Publishing Group Limited (BMJ) and may not have been peer-reviewed. Any opinions or recommendations discussed are solely those of the author(s) and are not endorsed by BMJ. BMJ disclaims all liability and responsibility arising from any reliance placed on the content. Where the content includes any translated material, BMJ does not warrant the accuracy and reliability of the translations (including but not limited to local regulations, clinical guidelines, terminology, drug names and drug dosages), and is not responsible for any error and/or omissions arising from translation and adaptation or otherwise.

Open access This is an open access article distributed in accordance with the Creative Commons Attribution Non Commercial (CC BY-NC 4.0) license, which permits others to distribute, remix, adapt, build upon this work non-commercially, and license their derivative works on different terms, provided the original work is properly cited, appropriate credit is given, any changes made indicated, and the use is non-commercial. See: http://creativecommons.org/licenses/by-nc/4.0/.

ORCID ID

MengChen Zou http://orcid.org/0000-0003-1409-4645

\section{REFERENCES}

1 International Diabetes Federation. IDF diabetes atlas. Brussels, Belgium: International Diabetes Federation, 2019.

2 Shah AD, Langenberg C, Rapsomaniki E, et al. Type 2 diabetes and incidence of cardiovascular diseases: a cohort study in 1.9 million people. Lancet Diabetes Endocrinol 2015;3:105-13.

3 Tousoulis D, Kampoli A-M, Stefanadis C. Diabetes mellitus and vascular endothelial dysfunction: current perspectives. Curr Vasc Pharmacol 2012;10:19-32.

4 Rask-Madsen C, King GL. Vascular complications of diabetes: mechanisms of injury and protective factors. Cell Metab 2013;17:20-33.

5 Shah MS, Brownlee M. Molecular and cellular mechanisms of cardiovascular disorders in diabetes. Circ Res 2016;118:1808-29. 
6 Ross R. Atherosclerosis--an inflammatory disease. N Engl J Med 1999;340:115-26.

7 Lei H, Romeo G, Kazlauskas A. Heat shock protein 90alphadependent translocation of annexin II to the surface of endothelial cells modulates plasmin activity in the diabetic rat aorta. Circ Res 2004;94:902-9.

8 Lazaro I, Oguiza A, Recio C, et al. Targeting Hsp90 ameliorates nephropathy and atherosclerosis through suppression of NF$\kappa \mathrm{B}$ and STAT signaling pathways in diabetic mice. Diabetes 2015;64:3600-13.

9 Kim J, Jang S-W, Park E, et al. The role of heat shock protein 90 in migration and proliferation of vascular smooth muscle cells in the development of atherosclerosis. J Mol Cell Cardiol 2014;72:157-67.

10 Madrigal-Matute J, López-Franco O, Blanco-Colio LM, et al. Heat shock protein 90 inhibitors attenuate inflammatory responses in atherosclerosis. Cardiovasc Res 2010;86:330-7.

11 Jayaprakash $\mathrm{P}$, Dong $\mathrm{H}$, Zou M, et al. Hsp90 $\alpha$ and $\mathrm{Hsp} 90 \beta$ together operate a hypoxia and nutrient paucity stress-response mechanism during wound healing. J Cell Sci 2015;128:1475-80.

12 Tsen F, Bhatia A, O'Brien K, et al. Extracellular heat shock protein 90 signals through subdomain II and the NPVY motif of LRP-1 receptor to Akt1 and Akt2: a circuit essential for promoting skin cell migration in vitro and wound healing in vivo. Mol Cell Biol 2013;33:4947-59.

13 Li W, Tsen F, Sahu D, et al. Extracellular Hsp90 (eHsp90) as the actual target in clinical trials: intentionally or unintentionally. Int Rev Cell Mol Biol 2013;303:203-35.

14 Emerging Risk Factors Collaboration, Sarwar N, Gao P, et al. Diabetes mellitus, fasting blood glucose concentration, and risk of vascular disease: a collaborative meta-analysis of 102 prospective studies. Lancet 2010;375:2215-22.

15 UK Prospective Diabetes Study Group. UK prospective diabetes study (UKPDS). VIII. study design, progress and performance. Diabetologia 1991;34:877-90.

16 Hennion DR, Siano KA. Diagnosis and treatment of peripheral arterial disease. Am Fam Physician 2013;88:306-10.

$17 \mathrm{He}$ X, Hu X, Ma X, et al. Elevated serum fibroblast growth factor 23 levels as an indicator of lower extremity atherosclerotic disease in Chinese patients with type 2 diabetes mellitus. Cardiovasc Diabetol 2017;16:77.

18 Shalash MAM, Rohoma KH, Kandil NS, et al. Serum sclerostin level and its relation to subclinical atherosclerosis in subjects with type 2 diabetes. J Diabetes Complications 2019;33:592-7.

19 Wang X, Shi J, Lu B, et al. Circulating heat shock protein 27 as a novel marker of subclinical atherosclerosis in type 2 diabetes: a cross-sectional community-based study. BMC Cardiovasc Disord 2020;20:198.

20 Bellini S, Barutta F, Mastrocola R, et al. Heat shock proteins in vascular diabetic complications: review and future perspective. Int J Mol Sci 2017;18:2709.

21 Jakhotia S, Sivaprasad M, Shalini T, et al. Circulating levels of Hsp27 in microvascular complications of diabetes: prospects as a biomarker of diabetic nephropathy. J Diabetes Complications 2018;32:221-5.

22 Shamaei-Tousi A, Stephens JW, Bin R, et al. Association between plasma levels of heat shock protein 60 and cardiovascular disease in patients with diabetes mellitus. Eur Heart J 2006;27:1565-70.

23 Sayed KM, Mahmoud AA. Heat shock protein-70 and hypoxia inducible factor- $1 \alpha$ in type 2 diabetes mellitus patients complicated with retinopathy. Acta Ophthalmol 2016;94:e361-6.
24 Ocaña GJ, Sims EK, Watkins RA, et al. Analysis of serum Hsp90 as a potential biomarker of $\beta$ cell autoimmunity in type 1 diabetes. PLoS One 2019;14:e0208456.

25 Businaro R, Profumo E, Tagliani A, et al. Heat-Shock protein 90: a novel autoantigen in human carotid atherosclerosis. Atherosclerosis 2009;207:74-83.

26 Zhu Y, Xian X, Wang Z, et al. Research progress on the relationship between atherosclerosis and inflammation. Biomolecules 2018;8:80.

27 Knapp M, Tu X, Wu R. Vascular endothelial dysfunction, a major mediator in diabetic cardiomyopathy. Acta Pharmacol Sin 2019;40:1-8.

28 Mudau M, Genis A, Lochner A, et al. Endothelial dysfunction: the early predictor of atherosclerosis. Cardiovasc J Afr 2012;23:222-31.

29 Ning D-S, Ma J, Peng Y-M, et al. Apolipoprotein A-I mimetic peptide inhibits atherosclerosis by increasing tetrahydrobiopterin via regulation of GTP-cyclohydrolase 1 and reducing uncoupled endothelial nitric oxide synthase activity. Atherosclerosis 2021;328:83-91.

30 Frostegård J, Zhang Y, Sun J, et al. Oxidized Low-Density Lipoprotein (OxLDL)-Treated Dendritic Cells Promote Activation of T Cells in Human Atherosclerotic Plaque and Blood, Which Is Repressed by Statins: microRNA let-7c Is Integral to the Effect. J Am Heart Assoc 2016;5:e003976.

31 Rahman M, Steuer J, Gillgren P, et al. Induction of dendritic cellmediated activation of $\mathrm{T}$ cells from atherosclerotic plaques by human heat shock protein 60. J Am Heart Assoc 2017;6:e006778.

32 Liu A, Ming JY, Fiskesund R, et al. Induction of dendritic cellmediated T-cell activation by modified but not native lowdensity lipoprotein in humans and inhibition by annexin A5: involvement of heat shock proteins. Arterioscler Thromb Vasc Biol 2015;35:197-205.

33 Profumo E, Buttari B, Tinaburri L, et al. Oxidative stress induces Hsp90 upregulation on the surface of primary human endothelial cells: role of the antioxidant 7,8-dihydroxy-4-methylcoumarin in preventing Hsp90 exposure to the immune system. Oxid Med Cell Longev 2018;2018:1-9.

34 Bäck M, Yurdagul A, Tabas I, et al. Inflammation and its resolution in atherosclerosis: mediators and therapeutic opportunities. Nat Rev Cardiol 2019;16:389-406.

35 Low Wang CC, Hess CN, Hiatt WR, et al. Clinical Update: cardiovascular disease in diabetes mellitus: atherosclerotic cardiovascular disease and heart failure in type 2 diabetes mellitus mechanisms, management, and clinical considerations. Circulation 2016;133:2459-502.

36 Ambade A, Catalano D, Lim A, et al. Inhibition of heat shock protein 90 alleviates steatosis and macrophage activation in murine alcoholic liver injury. J Hepatol 2014;61:903-11.

37 Needham LA, Davidson AH, Bawden LJ, et al. Drug targeting to monocytes and macrophages using esterase-sensitive chemical motifs. J Pharmacol Exp Ther 2011;339:132-42.

38 Kansakar U, Jankauskas SS, Gambardella J, et al. Targeting the phenotypic switch of vascular smooth muscle cells to tackle atherosclerosis. Atherosclerosis 2021;324:117-20.

39 Madrigal-Matute J, Fernandez-Garcia CE, Gomez-Guerrero C, et al. Hsp90 inhibition by 17-DMAG attenuates oxidative stress in experimental atherosclerosis. Cardiovasc Res 2012;95:116-23. 